\title{
Nonunion of Osteoporotic Vertebral Fractures: Clinical Characteristics and Surgical Treatment
}

\author{
Genlin Wang and Huilin Yang* \\ Department of Orthopaedics, The First Affiliated Hospital of Soochow University, \\ Suzhou, Jiangsu Province,
}

China

\section{Introduction}

Osteoporotic vertebral fractures (OVFs) are a frequently encountered clinical problem with an estimated incidence of 700,000 per year in the United States. Additionally, they are becoming more common as the median age of the population continues to increase. ${ }^{1-2}$ OVFs may be a sentinel sign of failing health in elderly patients. The degree of kyphosis correlates well with the patient's physical function, the risk of further fractures, compression of the spinal cord, and pulmonary function. ${ }^{3-5}$ Any of these factors may contribute to an increased mortality. ${ }^{4}, 6-7$ Patients with OVFs, who are refractory to conservative treatments, have been operated on by vertebroplasty or kyphoplasty over the past years. ${ }^{8-16}$ The fracture nonunion of OVF's has recently become an interesting topic of focus. This nonunion is often unrecognized and left untreated. This is unfortunate since, unlike acute vertebral compression fractures (VCFs), nonunion does not heal with time and will be a continued source of chronic pain and disability for the patient. 17 The aim of this article is to review the etiology of the fracture nonunion, clinical situation, imaging characteristics, and surgical treatment of the nonunion. Vertebroplasty and kyphoplasty, two recently developed operative procedures, will be reviewed and discussed in the management of OVFs.

\section{Etiology}

The etiology of the nonunion of OVFs is not very clear as there are many factors that can cause the nonunion. Some scholars ${ }^{18-19}$ believed that osteoporotic patients had a lower ability of osteogenesis in addition to their age-related microarchitectural deterioration of vertebrae which would subsequently lead to the nonunion or delayed union. There is evidence of this hypothesis from animal models. Namkung-Matthail et al ${ }^{20}$ showed a $40 \%$ reduction of callus formation in the cross-sectional area and a $23 \%$ reduction in bone mineral density in the healing femur of an osteoporotic rat model. There are several possible explanations for this effect. Bergman et al ${ }^{21}$ reported that there might be fewer mesenchymal stem cells (MSCs) in osteoporotic mice. They also stated that defects in the number and proliferative potential of MSCs might underlie age-related defects in osteoblast number and function. This may explain the age-related decrease in the number of osteoblasts. ${ }^{18}$ Rodriguez et al ${ }^{19}$ also reported mesenchymal stem cells in post-menopausal women differed from those in the premenopausal

${ }^{*}$ Corresponding Author 
by having a lower rate of growth as well as a deficiency in their ability to differentiate along the osteogenic lineage. Thus, vertebral fractures in elderly patients with severe osteoporosis may experience nonunion. This indicates that the ability to form bone is reduced in elderly patients with severe osteoporosis or deteriorated bone metabolism.

The nonunion of OVFs is thought to be related to avascular necrosis of the vertebral body and has been referred to as Kummel's disease of the spine.22-23 Ratcliffe ${ }^{24}$ has verified vascular supply in the anterior region beneath the superior endplate is the most tenuous by microarteriography. OVFs often occur in the anterior vertebrae where blood supply is easily destroyed which can lead to nonunion. This may explain why intraosseous clefts occurred primarily in the anterosuperior portion of the vertebral body. ${ }^{14,17}$ Baba et al ${ }^{25}$ believed that fibrous granulation tissue and necrotic bone in collapsed vertebral bodies changed vascular supply in the injured region and influenced the fracture union. This fibrous granulation tissue and necrotic bone result in the formation of pseudarthroses. ${ }^{26} \mathrm{~A}$ vascular insult can cause ischemic necrosis of the vertebral body and form the intraosseous clefts, 22, 27 leading to delayed union or nonunion ${ }^{28}$. Recent studies have shown that these clefts are frequent and represent fracture nonunion in patients with OVFs. ${ }^{29-31}$

However, Kim et al 32 reported 67 vacuum phenomena among 652 osteoporotic VCFs and discussed that biomechanics, not ischemic or avascular theory, may play an important role in this phenomenon. Yuan et al ${ }^{33}$ biomechanically demonstrated the thoracolumbar junction is the spinal region which receives the greatest dynamic load, and therefore may predispose to fracture nonunion.

Infections, steroids, radiotherapy, angiitis, pancreatitis, cirrhosis, alcoholism, atherosclerosis, old age and osteoporosis are considered to be high risk factors of OVFs to progress to nonunion. We find old age and osteoporosis are major risk factors, this may be related to our case-selection. 34

\section{Clinical situation}

There is no epidemiological data about incidence and age of onset. The nonunion of OVFs mainly occurs at the thoracolumbar junction.14, 17, 32 Most of the patients have no nerve lesion. The cardinal symptom is back pain with a certain feature that is distinctly proportional to activity and position. The pain is almost completely relieved by rest, most often in a lateral decubitus position, while symptoms return as soon as the spine is loaded in an attempt to sit, stand, or walk.16-17 These patients' pattern of pain is highly suggestive of this diagnosis. The back pain may be attributed to pseudarthrosis or to spinal deformity such as kyphosis or kyphoscoliosis which can produce a kaleidoscope of problems. ${ }^{35}$ However, motion of this intravertebral dynamic mobility is the primary cause of severe back pain. 14, 16, 36 Toyone et al 37 examined 100 consecutive patients with OVFs, and analyzed changes in vertebral wedging rate between the supine and standing position, and its association with back pain. There was a significant correlation between the changes in vertebral wedging rate and back pain and between the supine and standing position and back pain. This finding gives insight into the pathogenesis of the back pain.

\section{Imaging features}

The nonunion of OVFs may show intravertebral clefts ${ }^{31}$ or so-called vacuum phenomena 17 , 22,32 on vertebral imaging views most of which locate in the anterior region of vertebral 
body. ${ }^{14,} 17$ These clefts indicating fracture nonunion can easily be missed on standing lateral radiographs. ${ }^{29-31}$ However, they can be accentuated on lateral view radiographs with hyperextension. ${ }^{17,22,32}$

Peh et al ${ }^{38}$ reported vacuum phenomena in only $9 \%$ of patients in a retrospective study of lateral radiographs thus reflecting the poor sensitivity of lateral radiographs in detecting the clefts. McKiernan et al ${ }^{14}$ reported 50 consecutive patients with 82 OVFs in a prospective radiographic study and stated that clefts were detectable by standing lateral radiography in $14 \%$ of the cases, by supine cross-table radiography in $64 \%$, and MRI in $96 \%$. A cleft can be detected on T2-weighted MRI as an area of high or low signal intensity depending on whether it contains fluid or gas and on the repositioning of the patient's spine with time. ${ }^{39,40}$ However, recent studies ${ }^{13}, 17$ have reported that clefts of the fracture nonunion show high signal intensity on T2-weighted MRI. The clearly defined hyperintense intraosseous signal observed on T2-weighted sagittal MR13, 17, 41 may yet be a proven pathognomonic of this diagnosis. However, MRI may lead to false positives. Lane et al 31, in a retrospective analysis, reported intravertebral clefts in $31.8 \%$ of patients during percutaneous vertebroplasty, $52.8 \%$ of which had been detected on pre-operative MRI.

No cleft can be observed on a fresh-fractured vertebrae. ${ }^{37}$ Only in the absence of fracture union and with persistent mobility may clefts appear with their margins becoming increasingly sclerotic with time. $14,17,37$ Dynamic mobility, a recently recognized property of some osteoporotic vertebral compression fractures, may also appear. Dynamic mobility, ${ }^{42} \mathrm{a}$ change of vertebral height or configuration with changes in body positioning, is demonstrated by stress views in x-rays. ${ }^{14},{ }^{41}$ It can be determined when anterior vertebral height varies when comparing standing with supine lateral radiographs. ${ }^{14}$ The characteristics and significance of dynamic mobility are not well investigated. The OVFs is usually associated with intravertebral clefts and greater fracture severity.14, 17, 29-30, 43 Yoon et al ${ }^{17}$ believed motion of the endplates at the level of the fracture and an intraosseous vacuum sign represented a persistent, mobile nonunion. Jang et al ${ }^{41}$ also thought the changes in the anterior vertebral height on the dynamic lateral flexion and extension views confirmed intravertebral fracture nonunion.

Flexion/extension or standing/supine lateral radiographs reveal that mobile fractures are capable of postural correction by extension of the spine ${ }^{35}$. Substantial correction of kyphosis and anterior vertebral height can be corrected by extended posture. Kyphoplasty or vertebroplasty in addition to this extended posture can also correct the spinal instability that results from the mobile vertebral body. ${ }^{41}$ The restoration of vertebral body height might not only be position dependent, but time dependent as well. McKiernan et al ${ }^{14}$ had 14 patients with OVFs confined to the supine position overnight. These patients had additional vertebral height restoration. He termed this delayed postural vertebral fracture reduction "latent mobility." Dynamic mobility and latent mobility are undoubtedly manifestations of the same process of fracture nonunion. The importance of postural reduction should not be underestimated. The mobility can contribute significantly to vertebral height restoration. Using the technique of postural reduction may result in sufficient vertebral height restoration to allow vertebroplasty to be safely performed in some patients in whom the procedure had otherwise been deemed technically impossible or unsafe. ${ }^{14-15}$ 


\section{Treatment}

Most OVFs are managed with a short period of rest or activity modification, narcotic analgesics, and a brace. ${ }^{44}$ However, patients with fracture nonunion that are refractory to conservative treatments continue to have persistent back pain, progressive vertebral body collapse and kyphosis, and mobility of the fracture. ${ }^{17}$ These patients often need vertebroplasty or kyphoplasty intervention to make back pain disappear.12, 30-32 However, there is not a consensus on whether to select vertebroplasty or kyphoplasty.

Some scholars $15,45,46$ have that believed percutaneous vertebroplasty is effective for treating the fracture nonunion. Ha et $\mathrm{al}^{45}$ found the difference between patients with and without a cleft in the Oswertry Disability Index (ODI) and visual analog scale (VAS) scores at the final follow-up was not statistically significant. This agrees with the results of McKiernan et al. ${ }^{29}$ Krauss et al 46 also found pain reduction to be the same in both groups, but patients with intravertebral clefts showed a significant reduction of the kyphosis angle compared to noncleft patients during vertebroplasty.

Injecting cement into part of an intraosseous cleft will allow even cement filling of the entire cleft. Chen et $\mathrm{al}^{15}$ believed that a compression fracture with a vacuum cleft could be treated successfully with a uni-pedicle approach. Enlargement of the cleft by postural reduction can restore the vertebral body height in mobile fractured vertebrae with nonunion. Thus, Krauss et $\mathrm{al}^{46}$ believed that kyphoplasty is not necessary for the nonunion. However, Garfin et al ${ }^{9}$ and Yoon et al ${ }^{17}$ thought kyphoplasty offers the additional advantages of restoring vertebral body height and correcting kyphosis with the use of sufficient cement volume. Conversely, they believed that vertebroplasty probably led to inadequate initial fixation of a mobile nonunion which would result in clinical failure. Grohs et al ${ }^{16}$ carried an open prospective investigation of the efficacy of balloon kyphoplasty in the treatment of intravertebral pseudarthrosis. This study found that the extent of reduction of kyphosis and the duration of pain relief differed in regards to the type of fracture. In case of moderate to severe kyphosis occurring at thoracolumbar junction followed by nonunion of osteoporotic vertebral fractures, the results of verterboplasty or kyphoplasty treatment in view of reduction of kyphosis and loss of kyphosis are limited. To enable a better comparison of kyphosis reduction by vertebroplasty and kyphoplasty, a prospective study comparing both procedures should be performed.

Although percutaneous vertebroplasty and percutaneous kyphopalsty offer an efficient and safe treatment option, they are not free of complications. The main complication is polymethyl methacrylate (PMMA) leakage. Reported PMMA leakage rates vary. By CT scan after vertebroplasty, Jung et al ${ }^{13}$ found that the leakage rate was $55.5 \%$ in patients with clefts and $51.0 \%$ in patients without clefts (i.e. no significant difference). Ha et al ${ }^{45}$ compared the results of vertebroplasty in OVFs with and without clefts. More leakage occurred in the presence of a cleft with an incidence of $86.7 \%$. These findings were consistent with those of Yeom et al 47-48. This higher rate, compared to that of compression fractures without intravertebral vacuum clefts, may be attributed to the presence of a cleft. However, Krauss et al46 compared the occurrence of cement leaks after vertebroplasty. Cement leakage occurred in $18.2 \%$ of cases with clefts and in $46 \%$ of regular osteoporotic fractures without clefts. Patients with intravertebral clefts have a significantly lower risk of experiencing cement leakage during vertebroplasty and usually require a smaller amount of cement per 
vertebra. The reason might be that an intravertebral cleft is an avascular process surrounded by a fibrocartilaginous membrane.

Cement leakage types differed in osteoporotic compression fractures with and without intravertebral vacuum clefts. Jung et $\mathrm{al}^{13}$ reported that the leakage types were intradiscal $(65.0 \%)$, perivertebral venous $(25 \%)$, epidural $(5 \%)$, and foraminal $(5 \%)$ in compression fractures with clefts; and epidural (44.0\%), perivertebral venous (32\%), and intradiscal $(24 \%)$ in those without clefts. A significant difference was found between the most frequent types in both groups $(P=0.006, P=0.003$, respectively). Intradiscal type was $65 \%$, lower than the $79 \%$ reported by Peh et al. ${ }^{38}$. Krauss et $\mathrm{al}^{46}$ found that there was one cement leakage into a paravertebral vein in the cleft group while other leakage was through fractured endplates into the intervertebral discs. Higher leakage of the intradiscal type may be associated with intravertebral clefts. This suggestion is based on the findings that leakage into the disc almost always occurred at the location of the cleft as reported in the series of Peh et al. ${ }^{38}$ It is important to note that the risk of cement leakage is generally less in kyphoplasty than for percutaneous vertebroplasty because the bone cement is injected under lower pressure and can be more viscous when injected.16, 17, 49 We also found the advantages of kypjoplasty over vertebroplasty are lower incidence of PMMA leakage and better correction of kyphotic deformity for nonunion of OVFs. ${ }^{50}$

\section{Conclusion}

OVFs, like other fractures, may develop nonunion which can often go unrecognized. There are many factors that cause the nonunion such as lower ability of osteogenesis and agerelated microarchitectural deterioration of vertebrae and avascular necrosis of the vertebral body. Also, biomechanics may predispose to fracture nonunion. The nonunion of OVFs may show intravertebral clefts on vertebral imaging views. These intravertebral clefts most often locate in the anterior region of the vertebral body. Flexion/extension or standing/supine lateral radiographs can reveal fracture mobility. The importance of postural reduction should not be underestimated. Substantial correction of kyphosis and the anterior vertebral height may be obtained by an extended posture for spinal instability caused by mobility of the vertebral body. The cardinal symptom is back pain which is refractory to conservative treatments. These patients often need operative intervention. At present, the best surgical treatment option may be vertebroplasty and kyphoplasty. However, the long-term outcome of cement injection into the vertebral body is unclear. It is possible that injected cement may increase the stresses at adjacent levels and thus increase the likelihood of fractures at those levels. Development of bone cements with good long-term biocompatibility and mechanical properties that are similar to vertebrae may be a better and more viable solution.

\section{References}

[1] Riggs BL, Melton LJ 3rd. Involutional osteoporosis. N Engl J Med, 1986, 314: 1676-1686.

[2] Rao RD, Singrakhia MD. Painful osteoporotic vertebral fracture: pathogenesis, evaluation, and roles of vertebroplasty and kyphoplasty in its management. J Bone Joint Sug ( Am ) 2003, 85-A(10):2010-2022.

[3] Pluijm SM, Tromp AM, Smit JH, Deeg DJ, Lips P. Consequences of vertebral deformities in older men and women. J Bone Miner Res 2000;15:1564-72. 
[4] Kado DM, Browner WS, Palermo L, et al. Vertebral body fractures and mortality in older women: a prospective study. Arch Intern Med 1999;159:1215-20.

[5] Yang HL, Zhao LJ, Liu JY, et al. Changes of Pulmonary Function for Patients With Osteoporotic Vertebral Compression Fractures After Kyphoplasty. J Spinal Disord Tech, 2007, 20: 221-225.

[6] Linville DA 2nd. Vertebroplasty and kyphoplasty. South Med J 2002;95:583-7.

[7] Cotten A, Boutry N, Cortet B, et al. Percutaneous vertebroplasty: state of the art. Radiographics, 1998; 18:311-20.

[8] Cortet B, Cotton A, Boutry N, et al. Percutaneous vertebroplasty in the treatment of osteoporotic vertebral compression fractures. J Rheumatol 1999;26:2222-8.

[9] Garfin SR, Yuan HA, Reiley MA. New technologies in spine: kyphoplasty and vertebroplasty for the treatment of painful osteoporotic compression fractures. Spine. 2001;26:1511-1515.

[10] Peters K, Guiot B, Martin P, et al. Vertebroplasty for osteoporotic compression fractures: current practice and evolving techniques. Neurosurgery 2002;51:96-103.

[11] Berlemann U, Franz T, Orler R, et al. Kyphoplasty for treatment of osteoporotic vertebral fractures: a prospective non-randomized study. Eur Spine J 2004;13:496501.

[12] Carlier RY, Gordji H, Mompoint DM, et al. Osteoporotic vertebral collapse: percutaneous vertebroplasty and local kyphosis correction. Radiology. 2004;233:891-898.

[13] Jung JY, Lee MH, Ahn JM. Leakage of polymethylmethacrylate in percutaneous vertebroplasty: comparison of osteoporotic vertebral compression fractures with and without an intravertebral vacuum cleft. J Comput Assist Tomogr, 2006, 30: 501506.

[14] McKiernan F, Faciszewski T. Intravertebral clefts in osteoporotic vertebral compression fractures. Arthritis Rheum, 2003, 48: 1414-1419.

[15] Chen LH, Lai PL, Chen WJ. Unipedicle percutaneous vertebroplasty for spinal intraosseous vacuum cleft. Clin Orthop, 2005, 435: 148-153.

[16] Grohs JG., Matzner M, Trieb K, et al. Treatment of intravertebral pseudarthroses by balloon Kyphoplasty. J Spinal Disord Tech, 2006, 19: 560-565.

[17] Yoon ST, Qureshi AA, Heller JG, et al. Kyphoplasty for salvage of a failed vertebroplasty in osteoporotic vertebral compression fractures: case report and surgical technique. J Spinal Disord Tech, 2005, 18: S129-S134.

[18] D'Ippolito G, Schiller PC, Ricordi C, et al. Age-related osteogenic potential of mesenchymal stromal stem cells from human vertebral bone marrow. J Bone Miner Res, 1999, 14: 1115-1122.

[19] Rodriguez JP, Garat S, Gajardo H, et al. Abnormal osteoporotic patients is reflected by altered mesenchymal stem cells dynamics. J Cell Biochem, 1999, 75: 414-23.

[20] Namkung-Matthail H, Appleyard R, Jansen J, et al. Osteoporosis influences the early period of fracture healing in a rat osteoporotic model. Bone 2001;28:80-6.

[21] Bergman RJ, Gazit D, Kahn AJ, et al. Age-related changes in osteogenic stem cells in mice. J Bone Miner Res 1996;11:568-77.

[22] Maldaque BE, Noel HM, Malghem JJ. The intravertebral vacuum cleft: a sign of ischemic vertebral collapse. Radiology. 1978;129:23-29. 
[23] Assmann H, Montag M, Krzok G, Endert G. Related articles, links [Case reports of the Kummel-Verneuil syndrome] (German). Rev Med Chir Soc Med Nat Iasi. 1992;96:103106.

[24] Ratcliffe JF. The arterial anatomy of the adult human lumbar vertebral body. J Anat 1980;131:57-79.

[25] Baba H, Maezawa Y, Kamitani K, et al. Osteoporotic vertebral collapse with late neurological complications. Paraplegia, 1995, 33(5):281-289.

[26] Hasegawa K, Homma T, Uchiyama S. Vertebral pseudoarthrosis in the osteoporotic spine. Spine. 1998;23:2201-2206.

[27] Bhalla S, Reinus WR: The linear intravertebral vacuum: A sign of benign vertebral collapse. AJR Am J Roentgenol 170:1563-1569, 1998.

[28] Ito $Y$, Hasegawa $Y$, Toda K, et al. Pathogenesis and diagnosis of delayed vertebral collapse resulting from osteoporotic spinal fracture. Spine J. 2002;2:101-106.

[29] McKiernan F, Jensen R, Faciszewski T. The dynamic mobility of vertebral compression fractures. J Bone Miner Res. 2003;18:24-29.

[30] Mirovsky Y, Anekstein Y, Shalmon E, et al. Vacuum clefts of the vertebral bodies. AJNR Am J Neuroradiol. 2005;26:1634-1640.

[31] Lane JI, Maus TP, Wald JT, et al. Intravertebral clefts opacified during vertebroplasty: pathogenesis, technical implications, and prognostic significance. AJNR Am J Neuroradiol. 2002;23:1642-1646.

[32] Kim DY, Lee SH, Jang JS, et al. Intravertebral vacuum phenomenon in osteoporotic compression fracture: report of 67 cases with quantitative evaluation of intravertebral instability. J Neurosurg. 2004;100:24-31.

[33] Yuan HA, Brown CW, Phillips FM. Osteoporotic spinal deformity: a biomechanical rationale for the clinical consequence and treatment of vertebral body compression fractures. J Spinal Disord Tech, 2004;17: 236-242.

[34] Wang G, Yang H, Jiang WM, et al. Balloon kyphoplasty for osteoporotic vertebral compression fractures with osteonecrosis. Chin J surg, 2010, 48: 593-596.

[35] Hadjipavlou AG, Tzermiadianos MN, Katonis PG, Szpalski M. Percutaneous vertebroplasty and balloon kyphoplasty for the treatment of osteoporotic vertebral compression fractures and osteolytic tumours. J Bone J Jiont Surg (Br), 2005, 87: 1595-1604.

[36] Laloux P, Lefebvre S, Esselinckx W. Spinal cord compression secondary to vertebral aseptic osteonecrosis. Spine. 1991;16: 480-481.

[37] Toyone $\mathrm{T}$, Tanaka $\mathrm{T}$, Wada $\mathrm{Y}$, et al. Changes in vertebral wedging rate between supine and standing position and its association with back pain: a prospective study in patients with osteoporotic vertebral compression fractures. Spine, 2006, 31: 29632966.

[38] Peh WC, Gelbart MS, Gilula LA, Peck DD. Percutaneous vertebroplasty: treatment of painful vertebral compression fractures with intraosseous vacuum phenomena. AJR Am J Roentgenol 2003;180:1411-17.

[39] Malghem J, Maldague B, Labaisse MA, et al. Intravertebral vacuum cleft: changes in content after supine positioning. Radiology. 1993;187:483-487.

[40] Naul LG, Peet GJ, Maupin WB. Avascular necrosis of the vertebral body: MR imaging. Radiology. 1989;172:219-222. 
[41] Jang JS, Kim DY, Lee SH. Efficacy of Percutaneous Vertebroplasty in the Treatment of Intravertebral Pseudarthrosis Associated With Noninfected Avascular Necrosis of the Vertebral Body, Spine, 2003, 28: 1588-1592.

[42] Faciszewski T, McKiernan F. Calling all vertebral fractures: a consensus for comparison of treatment and outcome. J Bone Miner Res 2002; 17:185-191.

[43] McKiernan F, Faciszewski T. The modal distribution of osteoporotic vertebral compression fracture types. J Bone Miner Res 2002; 17(suppl):S260-S261.

[44] Kallmes DF, Jensen ME. Percutaneous vertebroplasty. Radiology 2003; 229:27-36.

[45] Ha KY, Lee JS, Kim KW, Chon JS. Percutaneous vertebroplasty for vertebral compression fractures with and without intravertebral clefts.J Bone Joint Surg (Br): 2006, 88: 629-633.

[46] Krauss M, Hirschfelder H, Tomandl B, Lichti G, Bär I. Kyphosis reduction and the rate of cement leaks after vertebroplasty of intravertebral clefts. Eur Radiol, 2006 16: 1015-1021.

[47] Yeom JS, Kim WJ, Choy WS, et al. Bone cement leakage in vertebroplasty for osteoporotic compression fractures. J Kor Ortho Asso 2003;38:293-300.

[48] Yeom JS, Kim WJ, Choy WS, et al. Leakage in cement in percutaneous transpedicular vertebroplasty for painful osteoporotic compression fractures. J Bone Joint Surg [Br] 2003;85-B:83-9.

[49] Lieberman IH, Dudeney S, Reinhardt M-K, et al. Initial outcomes and efficacy of "kyphoplasty" in the treatment of painful osteoporotic vertebral compression fractures. Spine. 2001; 26:1631-1638.

[50] Wang G, Yang H, Chen K. Osteoporotic vertebral compression fractures with an intravertebral cleft treated by percutaneous balloon kyphoplasty. J Bone Joint SurgBr. 2010; 92: 1553-1557. 


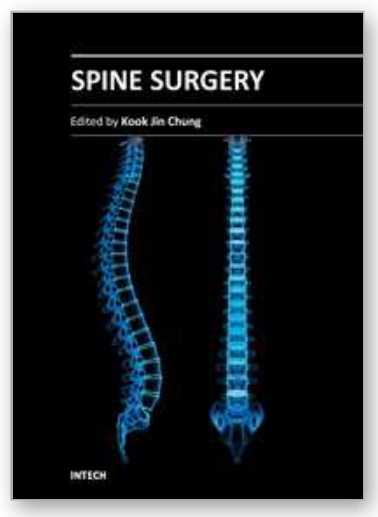

\author{
Spine Surgery \\ Edited by Dr. Kook Jin Chung
}

ISBN 978-953-51-0469-8

Hard cover, 148 pages

Publisher InTech

Published online 28, March, 2012

Published in print edition March, 2012

"Spine Surgery" is an authoritative and didactic textbook on the various fields of spine. It is written by many authors, internationally honorable experts to share their opinions with you. The chapters cover from anatomy of spine, spinal imaging technique, biology of spine, bone graft substitute, minimally invasive spinal surgery to even spinal deformity. It has many up to date results to help readers including university graduate students, medical instrumentation developers, and medical professionals including orthopaedic and neurosurgeons, rehabilitative professionals. The readers are provided with precious information and valuable guide in your daily practice.

\title{
How to reference
}

In order to correctly reference this scholarly work, feel free to copy and paste the following:

Genlin Wang and Huilin Yang (2012). Nonunion of Osteoporotic Vertebral Fractures: Clinical Characteristics and Surgical Treatment, Spine Surgery, Dr. Kook Jin Chung (Ed.), ISBN: 978-953-51-0469-8, InTech, Available from: http://www.intechopen.com/books/spine-surgery/nonunion-of-osteoporotic-vertebral-fracturesclinical-characteristics-and-surgical-treatment

\section{INTECH}

open science | open minds

\section{InTech Europe}

University Campus STeP Ri

Slavka Krautzeka 83/A

51000 Rijeka, Croatia

Phone: +385 (51) 770447

Fax: +385 (51) 686166

www.intechopen.com

\section{InTech China}

Unit 405, Office Block, Hotel Equatorial Shanghai

No.65, Yan An Road (West), Shanghai, 200040, China

中国上海市延安西路65号上海国际贵都大饭店办公楼405单元

Phone: +86-21-62489820

Fax: +86-21-62489821 
(C) 2012 The Author(s). Licensee IntechOpen. This is an open access article distributed under the terms of the Creative Commons Attribution 3.0 License, which permits unrestricted use, distribution, and reproduction in any medium, provided the original work is properly cited. 